\title{
Planning for Water Quality: Implementation of the NPDES Phase II Stormwater Program in California and Kansas
}

\author{
STACEY SWEARINGEN WHITE* \& MICHAEL R. BOSWELL** \\ *Graduate Program in Urban Planning. The University of Kansas. USA, \\ **City and Regional Planning, California Polytechnic State University, USA
}

\begin{abstract}
In the United States, the federal government is increasingly relying on local governments to implement policies that address the nation's lingering environmental problems. Yet, little is known about the factors that influence local level implementation of a federal mandate. This paper explores local government response to the NPDES Phase II Stormwater Program in California and Kansas by investigating local conditions, perceptions of the federal program, and implementer characteristics. The study found that fiscal resources, a well-educated public, positive perceptions of the federal policy, and co-operative planning efforts lead to better compliance with the mandate and a higher quality response.
\end{abstract}

\section{Introduction}

In the United States, the federal government is increasingly relying on local governments to implement policies that address the nation's lingering environmental problems. This study explores how local governments responded to a federal mandate that required implementation of a stormwater management program designed to improve the nation's water quality. The study focuses on exploring and establishing variables that explain local government performance with respect to the federal regulation. The context of the study is the Phase II Stormwater Program of the National Pollutant Discharge Elimination System (NPDES). This program, which is part of the amended Federal Water Pollution Control Act (FWPCA) of 1972, requires local governments to mitigate negative environmental impacts of urban stormwater runoff by developing and implementing best management practices (BMPs).

Correspondence Address: Stacey Swearingen White, Graduate Program in Urban Planning, The University of Kansas, 1465 Jayhawk Boulevard, 317 Marvin Hall, Lawrence, KS 66045-7614, USA.

Tel: (785) 864-3530. Fax: (785) 864-5301. Email: sswhite $a$ ku.edu 
The paper looks specifically at the Phase II Program in California and Kansas. California has a history and reputation of environmental protection, most notably through implementation of the California Environmental Quality Act, which requires most public and private development to undergo significant environmental impact assessment. Kansas has no such state environmental act. As a largely rural state, Kansas takes a more conservative approach to environmental protection, focusing more on traditional 'conservation' practices such as soil management. Given additional differences between these two states in terms of demographics, budgetary issues, land-use trends and so on, substantial differences are anticipated in their local governments' Phase II responses. Nevertheless, the study also expects to find some similarities of response due to the common federal guidance. Because the Phase II Program provides no financial assistance for local governments to implement its requirements, these entities widely perceived the Program as an unfunded mandate. For this reason, a similar pattern of minimal compliance is expected.

The research question that guides this study is: how and why does local government implementation of the NPDES Phase II Stormwater Program vary with respect to compliance and quality? To address this question, three additional questions were developed to focus the exploration. First, what are the local socioeconomic conditions in California and Kansas Phase II communities? Second, what were local government perceptions of the Phase II Program? Third, what learning. planning, evaluation, and decision processes did local governments use to respond to the Phase II Program?

\section{Context of the Study}

In December 1999, the United States Environmental Protection Agency (EPA) published the final ruling for the NPDES Phase II Stormwater Program (Federal Register Volume 64, Number 235). Since US environmental law is a type of administrative law (Kubasek \& Silverman, 1997), the NPDES Stormwater Program (both Phase I and Phase II) originated with the federal EPA and is administered by EPA regional offices or state-level environmental agencies, depending on whether EPA has authorized those state agencies to serve in such a role. ' Whereas much environmental law in the US is implemented at the state level, the NPDES Program requires implementation at the local level. The state or regional EPA offices are responsible for developing specific implementation guidance for local governments to follow in order to satisfy the federal rule.

The impetus for the NPDES Stormwater Program was a growing consensus that non-point source pollutants, particularly those contained in stormwater, are a continuing threat to the nation's water quality. The Program is the most significant national effort, and in many states (namely, those without their own water quality programs) the only effort. for solving the nation's non-point source water quality problem. Thus, the nation's 'eggs' are mostly in one 'basket'. According to recent studies, $45 \%$ of the assessed lakes and $39 \%$ of assessed rivers in the nation are polluted and agricultural and urban non-point sources are the leading causes (USEPA, 2000, 2002). As a result, the NPDES Stormwater Program must make a significant impact at the local government level, where it will be implemented. If the 
NPDES Stormwater Program is not planned or implemented effectively, then the nation's water quality will continue to deteriorate.

Whereas NPDES Phase I applies to municipal separate storm sewer systems (local governments) with populations of greater than 100 000, Phase II applies to local governments in urbanized areas of less than 100000 in population (and sometimes as small as a few thousand). The Phase II Program required these regulated local governments (primarily cities, counties and townships) to submit a Notice of Intent (NOI) to EPA or the appropriate state level regulatory agency by 10 March 2003. In California, the State Water Quality Control Board delegated this responsibility to the regions; in the case study this is the Central Coast Regional Water Quality Control Board (CCRWQCB). In Kansas, the responsible agency is the Kansas Department of Health and Environment (KDHE). In the NOI, applicants described the steps they would take to satisfy six Minimum Control Measures (MCMs) over a five-year period. In turn, these local governments were to receive a permit allowing them to continue to discharge stormwater runoff into US waters.

The Minimum Control Measures are: (1) Public Education and Outreach: (2) Public Involvement; (3) Illicit Discharge Detection and Elimination; (4) Construction Site Runoff Control; (5) Post-construction Runoff Control; and (6) Municipal Good Housekeeping. On its website, EPA provides detailed information concerning each measure and the best management practices (BMPs) that can be used to meet them. ${ }^{2}$ In addition to describing their BMPs, permit applicants provided measurable goals for each measure and an implementation schedule.

Because the NPDES Phase II Program requires local governments to develop BMPs for post-construction runoff control. there are clear implications for land-use planning, particularly site planning. The site planning techniques that are most helpful for minimizing polluted runoff are similar to so-called "smart growth" or "low impact design' techniques. ${ }^{3}$ For example, cluster development, on-site retention and vegetation buffers are ways to minimize water quality impacts of development. Whether or not any local governments would actually include such techniques as part of their Phase II response is questionable, because the flexibility of the six Minimum Control Measures allowed local governments to address their own unique circumstances and water pollution characteristics.

How these relatively small local governments would respond to a significant requirement to plan for water quality motivated our research. This is a unique federal mandate for small local governments, and there is little prior research to provide explanatory or predictive guidance. A look at the policy implementation literature gives more information.

\section{Policy Implementation}

The main body of theory guiding this research is policy implementation theory. The NPDES Phase II Stormwater Program requires local governments to implement policy that meets specific federal requirements. As such, it is appropriate to analyse this program within the theoretical foundations the policy implementation literature provides.

The primary task of the policy implementation literature has been explaining implementation behavior among various levels of government. For this study, 
interest in performance is actually a combined interest in compliance with a mandate such as the Phase II Stormwater Program and in the quality of the policy response. In other words, the aim of the study is to comment on both outcomes and outputs (Lester \& Goggin, 1998; Goggin et al.. 1990). The outcome is the "timely satisfaction of procedural requirements" outlined in the Phase II Program. The output, on the other hand, is the "extent to which program goals have been satisfied" (Goggin et al., 1990, p. 45).

Policy implementation scholars believe that implementation behavior varies predictably with respect to three features: (1) the environment in which implementation decisions and actions take place; (2) the attributes of the policy; and (3) the implementers and their organizations (Goggin et al., 1990, p. 20). Researchers have used a variety of approaches to investigate these variables, both independently and in conjunction with one another. Nearly all such analyses, however, focus on the state level (e.g. Game, 1979; Elazar, 1984; Ringquist, 1994). Studies of local government implementation are much less common.

Many studies that address questions of outcomes have emphasized the role of local conditions (e.g. Derthick, 1972; Pressman \& Wildavsky, 1973; Deyle \& Smith, 1998; Conroy \& Berke, 2004; Daley \& Layton, 2004). However, which local circumstances to explore varies considerably among researchers. In their recent study of Superfund site remediation, for example, Daley \& Layton (2004) considered the influence of local conditions ranging from the severity of contamination and number of responsible parties, to population density and household income. Conroy \& Berke's (2004) study of factors influencing sustainability in local plans operationalizes local context by measuring such variables as median home value and population change. Because a researcher must choose the relevant local conditions to investigate, variation in findings on this variable is likely.

With respect to policy attributes, a policy that is clear, consistent and perceived as credible is likely to result in more timely and thorough compliance (Goggin et al., 1990). How well a policy 'fits' a local context is also significant. In one of the few analyses of local government implementation of federal regulations, Mueller (1984) found that local governments implementing federal low-income housing policies were more likely to comply when a program was consistent with local mores. A policy's attributes may therefore interact with specific local conditions.

Research into the third type of explanatory variable, implementer characteristics, is also diverse. In another of the rare comprehensive analyses of local government implementation of a federally mandated law, Switzer (2001) identified a variety of local circumstances that affected compliance with the Americans With Disabilities Act (ADA). Of the nine causal variables she established, ${ }^{4}$ seven related to those persons and organizations charged with implementing local ADA programs. Who implementers are, how and what they learn about policy options, and how they interact with other policy officials are key elements of policy response.

Because studies of policy implementation at the local government level are uncommon, the investigation here of the Phase II Stormwater Program makes it possible to contribute additional insight into the theory and findings described above. As the methods section below describes, the analysis of compliance and quality (outcome and output) has been combined through a single evaluative scale, called 'performance'. For policy implementation factors affecting Phase II 
performance in California and Kansas, the same three variables noted above are explored. Specifically, the study expects to find that:

(1) Local conditions will influence performance;

(2) Perceptions of attributes of the Phase II Program will influence performance; and

(3) Characteristics of the Phase II implementers and their behavior will influence performance.

Figure 1 illustrates the theoretical model for investigating local government response to the Phase II Program. Local conditions are explored by analysing a host of socioeconomic variables relevant to the California and Kansas local governments. The study seeks to understand attributes of the Phase II Program by exploring perceptions of that program on the part of local governments. Finally, there is an exploration of the characteristics of the implementers and their organizations by analysing the learning, planning and evaluation, and decision processes local governments used to respond to Phase II.

\section{Research and Analysis Methods}

To investigate the research questions, a common protocol was adopted for gathering and analysing data. Three types of data were collected: documents, Census figures and interview responses. The document data were used to operationalize the dependent variable performance. Documents, Census figures and the interview responses were used to explore the three independent variables, local conditions, perceptions of the Program and implementer characteristics. The analysis included the use of both quantitative and qualitative research methods. Table 1 shows the data sources and the methods used to explore each independent variable.

The primary documents available were the Notices of Intent (NOIs) prepared by the Phase II respondents in both California and Kansas; these documents are essentially the plans in which local governments describe their BMPs and

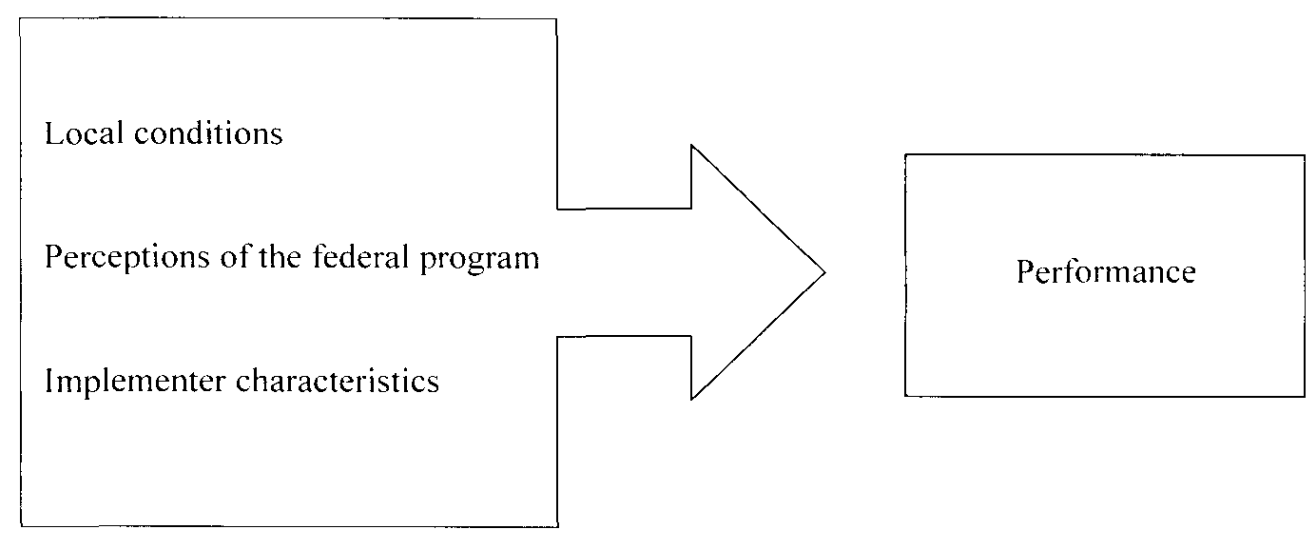

Figure 1. Proposed theoretical model for understanding performance in local government policy response. 
Table 1. Independent variables, data sources, and methods

\begin{tabular}{lll}
\hline Independent variables & Data sources & Methods \\
\hline $\begin{array}{l}\text { Local conditions } \\
\text { Total population } \\
\% \text { Annual growth rate } \\
\text { \% HS education or higher }\end{array}$ & Census data & Correlation \\
$\begin{array}{l}\text { Median household income }(\$) \\
\text { Median home value }(\$)\end{array}$ & & \\
$\%$ Families above poverty line & & \\
$\begin{array}{l}\text { Perceptions of the federal program } \\
\text { Implementer Characteristics }\end{array}$ & Interviews & Pattern matching \\
Learning process & Notices of intent & Pattern matching \\
Planning \& evaluation process & & Correlation \\
Decision process & & \\
\hline
\end{tabular}

implementation programs. Because these NOIs indicate the extent of compliance as well as the quality of the response, they became the primary means for operationalizing the dependent variable, performance in the study.

Each author reviewed all of the NOIs submitted to the relevant agency in both states (32 in California and 49 in Kansas). ${ }^{5}$ A four-point evaluative scale $(0-4)$ was established, based on criteria detailed in the EPA (2004) Phase II Fact Sheets (available at http://cfpub.epa.gov/npdes/stormwater/menuofbmps/menu.cfm). The Fact Sheets establish the minimum BMPs to be included for each MCM. A score of 0 was assigned when no BMPs was included, 1 when the minimum was not met, 2 for meeting the minimum, and a 3 or 4 for exceeding the minimum. For those MCMs where the minimum was exceeded, the Fact Sheet's 'guidelines for successful implementation' were used, which extend beyond the minimum requirements, to judge minimal versus substantial efforts. A score of 3 was assigned when the MCM contained some of the 'guidelines for successful implementation' and 4 when the MCM contained all of them or new ones. ${ }^{6}$ Thus, each local government was assigned a performance score for the NOI as a whole, by scoring all six MCMs and averaging (thus making this a continuous variable).

The document review also made note of specific aspects of the response in each local government. For example, it was discovered that some local governments had used a co-operative approach in developing and submitting their NOIs. These data informed the interview development and the analysis of the independent variables, particularly implementer characteristics.

After operationalizing performance in this way, the study drew on the second type of data, US Census figures, to explore the first of the independent variables, local conditions. The following six Census variables were examined: (1) total population; (2) annual growth rate; (3) percent of population with a high school education or higher: (4) median household income; (5) median home value; and (6) percent of families above the poverty line. Drawing from previous work in this area (Conroy $\&$ Berke, 2004; Daley \& Layton, 2004), these variables were selected as useful indicators of local conditions that might influence a local government's policy 
response. Larger or more rapidly growing cities, for example, may have different capacities for responding to a mandate such as NPDES Phase II than would their smaller and more slow-growing counterparts. A more educated and/or wealthier population may exert more pressure on local governments to adopt environmental protection policies.

Finally, semi-structured in-depth interviews were conducted with local officials in 18 of the local governments that submitted NOIs (see Appendix for the interview questions). This included eight local governments in California and 10 in Kansas. ${ }^{7}$ These interview data were used to further examine local conditions as well as the remaining two independent variables, perceptions of the federal program, and implementer characteristics. When selecting local governments for interviews, the authors sought to speak with individuals in places that represented a range of conditions in terms of location, demographics, and so on. In addition, each author interviewed the state agency employee most involved in carrying out the Phase II Program.

To examine the collected data, an extended case method was used (Burawoy, 1991). This method begins with hypotheses (propositions) developed from existing theory (here, the expectations noted in the preceding discussion of policy implementation) and reconstructs those hypotheses by bringing them into contact with the data. Unlike an experimental design, where hypotheses are confirmed or refuted, the extended case method is more exploratory, and seeks to add to or subtract from these hypotheses.

The primary quantitative method is a correlation analysis that shows the relationships between the Census data and the dependent variable (performance) from the primary research question. Performance was correlated with local conditions, as found in the Census data and documents described above. Correlation was also used to examine the relationship between a group NOI submittal and performance.

Qualitative analysis methods were used to enhance the understanding of the effects of local conditions, and to explore the remaining independent variables-perceptions of the federal program and characteristics of the implementers. The main analytical procedure used to examine the qualitative data was pattern matching (Patton, 1990: Robson, 1993; Yin, 1994). Using a goal-oriented coding approach (Patton, 1990; Robson, 1993), there was a search for evidence of themes related to the research questions and developed through the review of the literature. First, patterns for the cases in each state were identified. Overall patterns between the two states were then compared. These patterns become the links connecting data to theory in that they explain further the local governments' Phase II performance. Such patterns serve as a means of reconstructing existing theory on local government policy implementation. In the discussion of findings, patterns are presented as the dominant issues that emerged during the interviews.

\section{Findings and Discussion}

This section presents the findings with regard to the dependent variable-performance. It then presents the analysis of local conditions, policy attributes (examined here via perceptions of the Program), and implementer and organizational attributes as per the theoretical model presented in Figure 1. 


\section{Performance}

As noted earlier, the measure of performance is a composite of compliance and quality of response. The review of the NOIs and the performance scale established through the EPA Fact Sheets were used to determine the extent to which local governments both complied with the Phase II requirements and provided a high quality response. As Table 2 shows, just $16 \%$ of California local governments and $29 \%$ of Kansas local governments fully complied with the Phase II Program requirements. On the other hand, $5 \%$ of local governments (all located in Kansas) failed to comply on each of the six MCMs. ${ }^{8}$ The average number of MCMs complied within each state was 4.4 in California and 4.1 in Kansas.

When the data are broken down by individual MCM, they show that MCM 5 (Post-construction Runoff Control) had the lowest compliance level in California and MCM 4 (Construction Site Runoff Control) had the lowest compliance level in Kansas (see Table 3). Measures 1 and 2 had the highest compliance in each state.

The NOI data also indicate that only three of the 81 local governments (two California, one Kansas) on average substantially exceeded minimum compliance requirements and thus demonstrated a high quality response. ${ }^{9}$ When examined by individual MCM, the data show MCM 1 (Public Education and Outreach) had the highest number of high quality responses for California (far exceeding the others)

and MCM 5 (Post-Construction Runoff Control) had the highest number of high

Table 2. Overall local government compliance with minimum control measures

\begin{tabular}{lcc}
\hline & California & Kansas \\
\hline All 6 MCMs in compliance & $16 \%$ & $29 \%$ \\
5 MCMs in compliance & $41 \%$ & $10 \%$ \\
4 MCMs in compliance & $31 \%$ & $37 \%$ \\
3 MCMs in compliance & $9 \%$ & $8 \%$ \\
2 MCMs in compliance & $0 \%$ & $8 \%$ \\
l MCM in compliance & $3 \%$ & $0 \%$ \\
No MCMs in compliance & $0 \%$ & $8 \%$ \\
Number of cases & 32 & 49 \\
\hline
\end{tabular}

Table 3. Local government compliance with individual minimum control measures

\begin{tabular}{llcc}
\hline & & California & Kansas \\
\hline MCM 1 & Public education and outreach & $100 \%$ & $88 \%$ \\
MCM 2 & Public participation involvement & $94 \%$ & $88 \%$ \\
MCM 3 & Illicit discharge detection and elimination & $65 \%$ & $67 \%$ \\
MCM 4 & Construction site runoff control & $65 \%$ & $35 \%$ \\
MCM 5 & Post-construction runoff control & $48 \%$ & $63 \%$ \\
MCM 6 & Pollution prevention good housekeeping & $81 \%$ & $57 \%$ \\
Number of cases & & 32 & 49 \\
\hline
\end{tabular}


quality responses for Kansas (see Table 4). Thus, the combined examination of compliance and quality shows that most communities can be categorized as low to moderate performing and very few can be categorized as high performing.

\section{Local Conditions}

As noted above, several demographic variables were selected to provide a basic description of the local governments in each state and to operationalize local conditions. A difference of means tests on the averages of these variables shows that California and Kansas are remarkably similar on three of them: annual growth rate, median household income, and percent of families above the poverty level (see Table 5) ${ }^{10}$ In addition to these Census variables, the role (for California only) of coastal jurisdictions was explored.

The correlation analysis shows a significant positive relationship between the socioeconomic variables of median home value and percent of high school education or higher and the measure of performance by local governments (see Table 6). It is thought this indicates the relative fiscal advantage of these local governments from property and other tax revenues; they are better able to allocate personnel and other resources to preparation of the stormwater plans. In California, the interview data corroborate this observation in that communities with dedicated funding sources other than General Funds, on average performed better. While this did not hold true

Table 4. Local governments exceeding minimum control measure requirements

\begin{tabular}{llcc}
\hline & & California & Kansas \\
\hline MCM 1 & Public education and outreach & $59 \%$ & $0 \%$ \\
MCM 2 & Public participation/involvement & $3 \%$ & $2 \%$ \\
MCM 3 & Illicit discharge detection and elimination & $3 \%$ & $0 \%$ \\
MCM 4 & Construction site runoff control & $0 \%$ & $0 \%$ \\
MCM 5 & Post-construction runoff control & $9 \%$ & $4 \%$ \\
MCM 6 & Pollution prevention/good housekeeping & $6 \%$ & $0 \%$ \\
Average & & $14 \%$ & $1 \%$ \\
Number of cases & & 32 & 49 \\
\hline
\end{tabular}

Table 5. Differences in local conditions between California and Kansas

\begin{tabular}{lcccc}
\hline Local conditions & California & Kansas & t & Significance \\
\hline Total population & 123905 & 41307 & - & $*$ \\
\% Annual growth rate & 1.4 & 1.3 & - & $*$ \\
\% HS education or higher & 77.6 & 88.7 & - & $*$ \\
Median household income $(\$)$ & 48822 & 51372 & - & $*$ \\
Median home value $(\$)$ & 318903 & 109996 & - & $*$ \\
$\%$ Families above poverty line & 92.3 & 94.6 & - & \\
Number of cases & 32 & 49 & & \\
\hline
\end{tabular}

${ }^{*} 0.005$ level of significance. 
Table 6. Performance correlated with local conditions and response to the federal program

\begin{tabular}{lcc}
\hline & California & Kansas \\
\hline Local conditions & - & - \\
Total population & - & - \\
Annual growth rate & $.40^{1}$ & $.41^{2}$ \\
\% HS education or higher & - & - \\
Median household income & $.37^{1}$ & $.34^{1}$ \\
Median home value & $.37^{1}$ & - \\
\% Families above poverty line & $.47^{2}$ & - \\
Coastal jurisdiction & & $.47^{2}$ \\
Response to the federal program & - & 49 \\
Group submittal & 32 & \\
Number of cases &
\end{tabular}

'0.01 level of significance.

$=0.05$ level of significance.

for Kansas, it should be noted that the local governments in the highest scoring cooperative group are part of a county-funded stormwater management program in the state's wealthiest county. In addition to the findings related to fiscal advantage, it is reasonable to infer that significant correlations with high school education indicate that better educated communities are more likely to support programs that enhance environmental quality (for example, see Scott \& Willits, 1991). ${ }^{11}$

The correlation analysis indicates no correlation between population or population growth and the performance variable. This likely shows that size of the local government is less relevant with regard to capacity to respond to the Phase II requirements than their fiscal position. In other words, small local governments can respond just as successfully when sufficient funding is present.

Breaking up overall performance scores into sub-scores for each minimum control measure shows similar correlations, with the exception of MCM 5 (PostConstruction Runoff Control). This shows local governments' confusion over and inattention to this MCM compared to the others. Rance Walker, the KDHE representative most involved with the Phase II Program in Kansas, recalled that MCM 5 "involved considerable discussion and debate [on EPA's part] as to whether it should be included". If this is in fact the case, ensuing confusion might be expected. This finding is also supported by the fact that MCM 5 had the second lowest level of performance.

California coastal communities had higher quality scores than non-coastal communities. This may be because many stormwater runoff problems in California manifest themselves in beach closures. Stormwater quality problems may thus be more salient to a coastal community that has economic and quality of life interests in coastal recreation.

\section{Perceptions}

The attributes of Phase II stormwater policy have been analysed by examining the perceptions of the Program in California and Kansas local governments. These 
entities largely view the Phase II Program as a burden with three main dimensionscost, personnel and information. A strong majority of the 18 interviewees (five in California and eight in Kansas) mentioned cost as a primary element of their (mainly negative) perceptions of Phase II. Others (three interviewees in California and four in Kansas) specifically used the term 'unfunded mandate' to describe the program. In Kansas, local governments with a stormwater utility in place (four of the 10 places interviewed) expressed less concern with their overall capacities for responding to Phase II; nevertheless three of these four local governments still note that this program imposes a cost burden.

In addition to cost, local governments perceive a difficulty in devoting scarce personnel resources to their Phase II response. Only a few of the interviewees (three in California and two in Kansas) indicated that their communities have created an additional position in order to deal with Phase II (the three new California positions are half-time). Others were making do with existing staff resources at a time when workloads are already heavy. As one Kansas interviewee put it, "we've got less monies, less staff, less time. Where are the money and the time going to come from to meet all of these [requirements]?"

In California and Kansas, many local governments also felt information about the Phase II Program was less than clear and that shaped this sense of burden. Half of the California interviewees questioned whether the Program was appropriate for small jurisdictions or whether it would have any effect. One such interviewee remarked:

Phase II is window dressing. The BMPs are things that people say is the minimum that people need to do, but if that's all you do, you're not going to improve creek and ocean water quality in any measurable way. You've got to do a lot more than that.

Half of the Kansas interviewees indicated that they still had questions about the specifics of the Program. In both states, interviewees expressed frustration that at the time of the interviews, they did not yet have their permits. Despite the fact that the local governments had submitted their Notices of Intent over a year earlier, the CCRWQCB had failed to issue permits and was still in the process of negotiating with communities over the minimum requirements. ${ }^{12}$ Similarly, KDHE had yet to issue its permits. ${ }^{13}$ Without further guidance from the state or regional level as to the implementation requirements, these local governments were reluctant to try to address their cost and personnel shortages. In other words, a perceived lack of information about the specific requirements they would need to meet amplified local governments' perceived burdens with respect to cost and personnel.

This analysis reveals predominantly negative perceptions of the Phase II Program's attributes in both California and Kansas. In fact, no positive themes emerged as consistent in the interview data. Given this negative reception, the low performance levels overall among these local governments is not surprising. As will be described further below, concerns about cost, personnel and information have influenced the ways these local governments have responded to Phase II. More directly, it is argued that these negative perceptions contributed to mediocre performance. 


\section{Implementer Characteristics}

In order to comment on the characteristics of the implementers and their organizations, the final explanatory aspect of policy implementation, there was a look at the learning, planning and evaluation, and decision processes local governments used to respond to the Phase II Program. The choices local governments make with respect to these three processes reflect distinct aspects of both the individuals involved in the Phase II response as well as the larger organizational setting in which those individuals function. Each process is described separately and analysed together at the end of those descriptions.

Learning process. California and Kansas local governments have had a variety of learning experiences with respect to the Phase II Program. For the most part, however, practical considerations have governed these learning experiences. A large majority of those interviewed (six in California and eight in Kansas) had anticipated the effects of this program prior to its actual publication in the Federal Register. Based on the experiences of Phase I communities such as the City of Wichita, KS, these local governments had expected their pending involvement over a period of several years. Interestingly, one of the remaining Kansas interviewees did not become aware that they were subject to the Phase II program until the response deadline was only a matter of months away. One Kansas local government learned of the program when approached by the Kansas Consortium of cities who had joined forces to expedite the process.

Local governments learned of the specific Phase II requirements in a wide variety of ways, but there were three main sources of information: professional meetings, cooperative efforts, and websites. Professional meetings included seminars, workshops and conferences put on by groups such as the American Public Works Association (APWA), private consulting firms, public agencies, and, in California, the California Storm Water Quality Association. Half of the interviewees were involved in one of the two co-operative efforts in California or one of three in Kansas that emerged in response to the Phase II Program. These local governments learned about Phase II requirements through meetings they attended together, some of which were facilitated by consultants hired to expedite the response process. A majority of the interviewees (seven in California and six in Kansas) indicated that they also relied on Internet resources for learning about Phase II. The EPA Fact Sheets, which discuss each of the MCMs, were a prominent source of online information. Finally, four of eight California interviewees referenced the Model Urban Runoff Program, a joint effort among a variety of local and regional agencies to develop a model process and document for local governments to use in preparing their NOIs, as an important source of information.

Notably, CCRWQCB and KDHE played a relatively small role in the learning processes local governments in California and Kansas used. While these agencies apparently did participate in some of the aforementioned professional meetings, interviewees did not emphasize their role. On the contrary, roughly one-third of the interviewees (three in California and three in Kansas) specifically noted that their respective oversight agency, CCRWQCB or KDHE, had not been particularly helpful. As one California interviewee put it, there was "surprisingly very little 
information from the state in terms of what they really wanted to see". Similarly, a Kansas interviewee stated, "I have talked to KDHE a little bit in terms of this Phase II Program, but I kind of gather that they're gearing up for it just the same as I am. The information I got was rather limited". Thus, even though these state agencies are responsible for administering the Phase II program, they have not served as a major source of information for affected local governments.

Planning and evaluation process. In California and Kansas local governments, pragmatism was a dominant influence guiding the planning and evaluation process. This practical approach was especially prominent among the Kansas local governments, who, as one interviewee stated, sought to "roll up our sleeves and get it done". California interviewees also noted other influences, most notably a recognition of the opportunity to involve and educate the public and decision makers.

Local governments in California and Kansas sought to identify best management practices (BMPs) and measurable goals that were low cost and required minimal staff time to develop and implement. In all cases, the ability to take credit for stormwaterrelated activities that were already in place was an important evaluation tool, as this ability minimized both costs and personnel requirements. Less prevalently, some interviewees looked for BMPs that fit their local circumstances well.

To enhance their efforts, half of the interviewed California local governments had water quality and/or biological data that directly supported this process. One California interviewee said they had seven years of water quality trend data and another stated: "One of the first things we did ... in this was started collecting data". However, in Kansas only two of the 10 local governments had any water quality or biological data available for use in assessing the stormwater problem and developing solutions. Even in those two local governments, the links between these data and the Phase II planning and evaluation process were not readily apparent.

In California, half of the interviewees described a substantive role played by the local Planning Department in the planning and evaluation process. An additional two anticipated future involvement. However, such planning professional involvement in Kansas was present in only one of the interviewees' experience. While half of the Kansas interviewees indicated that they expected additional involvement of planners in the future, they had not yet made efforts to engage this involvement.

In California and Kansas, municipal staff were almost exclusively responsible for the evaluation process that took place, but engineers rather than planners played the key roles. These persons expressed a sense of being overworked and struggling to address all that Phase II required in addition to their other job responsibilities. Furthermore, in Kansas, most of these engineers had little or no previous experience with stormwater quality issues; they focused primarily on water quantity concerns.

Ultimately, most communities used a basic qualitative cost-effectiveness assessment in their planning and evaluation process, with the exception of a single California community that used a sophisticated 'priority matrix' for developing its NOI. While these processes the interviewees described varied in intensity and complexity, the common and overarching feature in both states was a pragmatic approach for planning and evaluation. 
Decision process. In California, six of eight stormwater programs went through review by elected officials before submittal, whereas in Kansas eight of 10 programs received review at the administrative level, by a City Manager, Public Works Director, or the like. In all cases the review process seemed to be more a formality than a rigorous program assessment. There was not evidence that the approval process in either state resulted in any program changes.

Unlike nearly all of their Kansas counterparts, three California local governments had or were planning to have the general public and/or citizen advisory boards review the stormwater program prior to final adoption. However, one California interviewee expressed concern that this level of public involvement may be problematic in that "there is this idea of developing the perfect wheel before you adopt it, not just adopt something that's pretty reasonable, get with it, and then we'll refine it in the next five years". Interestingly, the one Kansas interviewee who pursued a participatory process for both the planning and evaluation process and the decision process noted an opposite problem: stakeholders "came to a meeting once and then we'd never see them again".

Cost effectiveness was key to the decision process in both California and Kansas. Over half of the interviewees (four in California and six in Kansas) noted that they chose measures based on their low cost. One interviewee captured a common sentiment when he said, "[we are] trying to be realistic, so we just met the basic requirements. If we want to make the choice of doing more we will, but we don't want to be tied to it". In other words, communities were very aware of the binding nature of their Phase II response. Any aspirations of a more involved program were tempered by practical considerations.

In Kansas, pragmatism was also once again a dominant feature in the decision process. Because those staff members who were involved in their local government's Phase II response are largely the same staff who will implement the ensuing stormwater programs, this is not surprising. Local governments decided on BMPs and measurable goals that met several pragmatic criteria. Of these criteria, ease of implementation was paramount. Seven of the 10 Kansas interviewees indicated that they based their decisions on their ability to carry out the BMPs simply, with a minimum of time and personnel required.

Influence of learning, planning and evaluation, and decision processes on performance. These interviews revealed that California and Kansas local governments responded to the Phase II Program in broadly similar ways. They had similar processes for learning about it, planning for and evaluating it, and deciding on a local response. While interviewees in California local governments articulated a broader range of experiences with respect to some of these areas, overall, the differences are less prominent than the similarities.

The phenomenon of a group NOI submittal emerged in both the document analysis and the interviews. For Kansas, Table 5 shows a significant correlation between the measure of performance and whether or not the local government participated in a group submission. While this finding suggests the three Kansas coalitions performed better, closer examination of the documents and interview data impels a more nuanced understanding. The results of the three Kansas coalitions are quite different. While one such group did indeed produce higher quality NOIs, this is 
largely the result of a standardized adoption among group members of very comprehensive BMPs and measurable goals for MCM 1 (Public Education and Outreach) and MCM 2 (Public Participation/Involvement). A second coalition produced mixed results, with some local governments meeting or slightly exceeding requirements and others falling below. The third coalition submitted nearly identical NOIs for its five local governments, but achieved a sub-standard score for its efforts. In California, although this group correlation fell just below significance, the interview data showed the relationship to be important. From these findings, it appears that a co-operative response alone is insufficient to guarantee a higher quality policy response. Factors specific to the co-operative process, such as the role of consultants and the standardization of responses, deserve further analysis.

A final relationship evident in the interview data is the higher performance scores for California communities who referenced the Model Urban Runoff Program document as a useful source of information. This document was a joint effort among a variety of local and regional agencies with the intent of providing the local governments a model that could be used to meet the Phase II Program requirements. Apparently the effort was a success.

With respect to the themes that emerged in the learning, planning and evaluation. and decision processes, pragmatism was the most prominent overall pattern. Local governments in California and Kansas sought highly practical ways to learn about, evaluate, and decide on their Phase II response. In many ways, these response processes followed a predictable trajectory. As local governments learned about the Program through activities such as professional meetings (particularly engineering meetings), websites, and those co-operative efforts that formed in each state, they were left with the prevailing sense that this mandate imposed cost and personnel burdens. The planning, evaluation and decision processes that ensued from this learning process were therefore governed by the pragmatic considerations described above.

Although response strategies in California and Kansas included some glimmers of attention to the specific needs of the local government in question, these were overshadowed by concerns over making the response as cost-effective and easy-toimplement as possible. While this sort of pragmatic. 'just get it over with' response makes sense given the negative perceptions local governments had of the Phase II Program, it may have compromised performance. Unless communities take the time (and gather the data) necessary to craft a stormwater plan that responds to their own particular situation, that plan is less likely to be high quality.

\section{Conclusions and Directions for Future Research}

From the data analysed here, it is clear that local governments respond to a federal mandate such as the NPDES Phase II Stormwater Program in similar ways. The research contributes several insights into the understanding of policy implementation in a local government context, which are relevant to any nation with a federal system. The study found that performance behavior did in fact vary with: (1) local conditions (i.e. the implementation context); (2) perceptions of the program (i.e. attributes of the policy); and (3) characteristics of the implementers and their organizations. Figure 2 illustrates the specifics of these initial findings. 


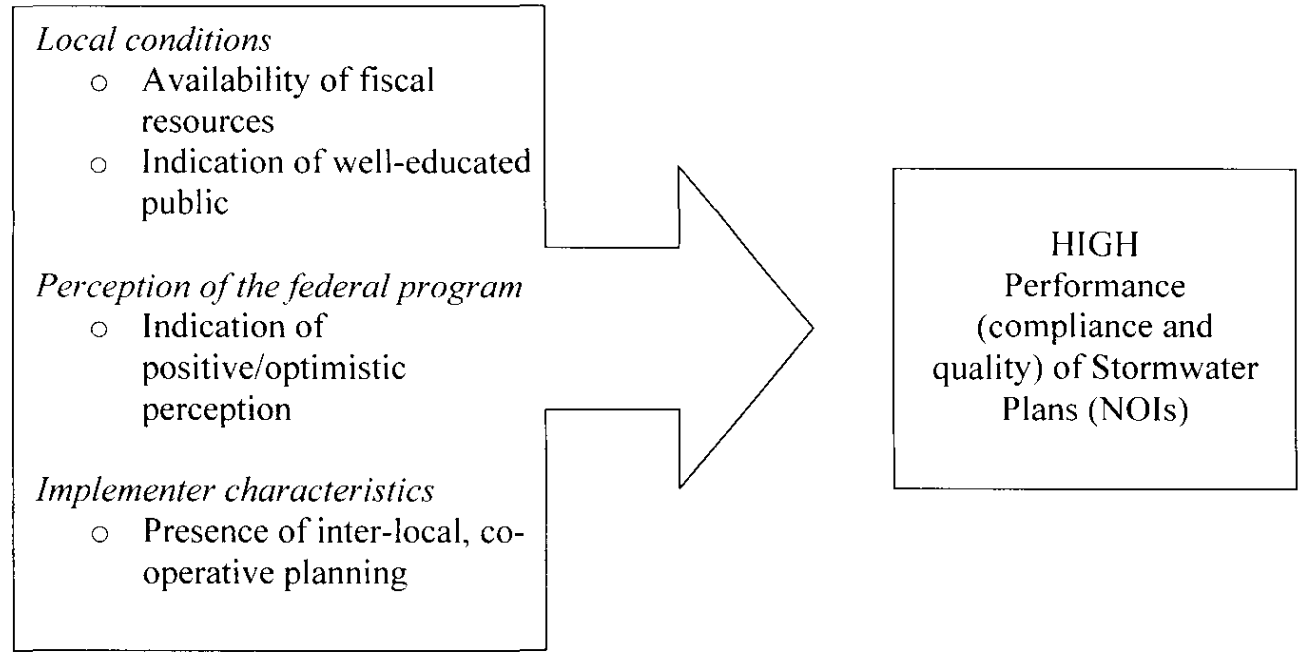

Figure 2. Empirical model for understanding performance in local government policy response for the Phase II Program.

With respect to local conditions, wealthier, more educated communities had higher levels of Phase II performance. This finding speaks to the fact that resources are a critical part of successfully implementing federal programs such as this one. However, community resources alone did not mitigate the largely negative views of Phase II that local governments hold. Similarly, the predominantly pragmatic processes local governments used to respond to Phase II revealed that response quality (output) was much less a concern than simply doing the bare minimum. Despite Phase II's emphasis on planning for local circumstances, then, it appears that this particular mandate has not motivated local governments to consider response quality in addition to simple compliance. This finding also likely relates to the local program managers" largely negative perceptions of the Phase II Program. Although it is no surprise that local governments do the minimum in response to mandates from higher levels of government, confirmation of it in this study suggests that federal policy makers continue to ignore this phenomenon.

With respect to the characteristics of the implementers and their organizations, there is some evidence that local governments who worked co-operatively performed better. The one exception in Kansas may relate to the pervasive sentiment of just getting this over with'. Therefore, it is thought that collaboration must be based on a goal of producing better outputs. There is also evidence from California to suggest that the availability of a model program based on regional conditions improved local government performance. These findings suggest a more important role for regional planning agencies, particularly in assisting in meeting a federal mandate. Regional planning agencies could provide the forum for collaborative planning efforts and for consolidation of technical knowledge.

Although the average performance of local governments in California and Kansas was mediocre at best, in some ways, these local governments have succeeded in providing a high quality response in areas one might not expect. For example, Public Education was the highest scoring MCM. Additional analysis is necessary to discern whether this was a function of the clarity of this particular measure or whether other 
factors are at work, such as the emphasis the relevant state agencies placed on the various components of the mandate (Deyle \& Smith, 1998). The individual characteristics of professionals in those local governments with higher quality responses are also worthy of further investigation. It is possible that these individuals have a higher sense of commitment to environmental issues, including water quality, and that this commitment influences their performance. However, this cannot be claimed definitively from the findings here.

From an environmental perspective, the results of the Phase II Stormwater Program will be difficult to assess for a number of years. However, it is possible to speculate as to their probable impacts. Clearly, local governments that comply with the Phase II requirements, even minimally, will be taking some steps towards reducing the adverse water quality impacts of their communities. The multi-faceted, flexible approach embodied in the Phase II Minimum Control Measures allows local governments to select options that work well for them. At the same time, these local governments must address significant aspects of the stormwater quality problem, from public education to municipal operations. It can be expected that insufficient capacities at the local government level will affect the water quality improvements that occur (or fail to occur) in our nation's waterways. Additional research in this area will enhance the insights developed here. For now, there is scepticism that substantial water quality improvements will occur within the current structure of federal mandates administered by state agencies and implemented by local governments.

Given this assessment, three recommendations are offered concerning federally mandated programs:

(1) Federal and state agencies should be proactive in assisting local governments in the identification and development of financial resources for meeting the federal program requirements. Moreover, when these federal programs are significant relative to the fiscal resources of small local governments, legislation should include new funding mechanisms.

(2) Federal and state agencies should provide incentives and facilitate co-operative efforts among local governments. This may have the added benefit of streamlining program management and technical support by the responsible oversight agency.

(3) State and regional agencies should work with local governments, professional associations, and consultants to develop a regional model for meeting the federal program requirements. The responsible oversight agency should then guarantee a more predictable review process for those local governments that base their plans on the regional model.

As local governments begin to implement more of their Phase II BMPs and to measure the goals they have set for themselves, future research will become more fruitful. Future research should expand the number of states included, develop additional measures in the three areas identified in the theoretical literature, and refine some of the variables used in this study (e.g. community wealth could be examined more directly through a close examination of municipal budgets). Further, to understand fully the effects of a mandate such as the NPDES Phase II Stormwater 
Program, it is important to observe the whole process as it unfolds over the next five years. Such study will reveal new answers as well as new questions.

\section{Acknowledgements}

The authors gratefully acknowledge funding for a research assistant provided by the University of Kansas Policy Research Institute. They are indebted to Erin Ollig, Jim Mayo, William J. Siembieda and Tammy L. Seale for their help. Thanks are also due to the three anonymous referees for their constructive and helpful comments.

\section{Notes}

1 Information on EPA's authorization of state agencies can be found at: http:/cfpubl.epa.govinpdes statestats.cfm?program_id $=12$

2 For example, for Measure 1 (Public Education and Outreach), EPA suggests the use of educational materials and strategies such as brochures or fact sheets and storm drain stenciling. For Measure 5 (Post-Construction Runoff Control). EPA lists a number of structural and non-structural BMPs. The former includes such measures as buffer zone ordinances, while the latter includes use of grassy swales. rain gardens, and so on.

3 The Center for Watershed Protection website (available at www.cwp.org) has an abundance of useful information related to these techniques.

4 These causal variables were: the position of the ADA co-ordinator within the municipal power structure; awareness among municipal staff about the requirements of the law; training for municipal staff at each level of service: participation and input from disabled persons; focus, leadership and composition of citizen commissions; financial resources; co-ordination and interaction with other municipalities; interaction or interest on the part of elected officials: knowledge about the number of disabled persons within the community or the services needed by those persons.

5 For California, the CCRWQCB Phase II local governments were examined as a sample of the state: this region encompasses coastal California from roughly Santa Cruz to Santa Barbara. For Kansas, all Phase II local governments in the state were examined. Although 51 local governments sent in a response to the state, only 49 were usable. The other two local governments failed to submit any specific information.

6 The scoring sheet developed is detailed on this point and available for future researchers; it is not included here due to its length.

7 In California, the local governments were: Monterey County, San Luis Obispo County, City of Marina, City of Monterey. City of San Luis Obispo, City of Gilroy. City of Lompoc and City of Santa Barbara. The Kansas local governments were: Shawnee County. City of Andover, City of Derby, City of Garden City, City of Lawrence. City of Lenexa, City of McPherson. City of Olathe, City of Parsons and City of Salina.

8 It should be noted that many Kansas local governments had particular difficulty with the requirement to describe their measurable goals for each MCM. In some instances. a local government would list BMPs for each MCM, but fail to indicate measurable goals. This resulted in lower average scores

9 This is counted as scoring above a 3 . which is a liberal standard. If the threshold is set at 3.5 then only one community substantially exceeded requirements.

10 The presence of one very large county in California skews its average population. Excluding this county, the average California population drops to 73626 .

11 Moreover, wealthier, better-educated communities may already be addressing many of the policy requirements, an issue the authors intend to explore in a subsequent article.

12 Five of the eight interviewees expressed frustration with the CCRWQCB review process and the fact that they had not been issued permits. They generally felt that the CCRWQCB was sending mixed signals.

$13 \mathrm{KDHE}$ issued the permits to all applicants in late Scptember 2004. 


\section{References}

Burawoy, M. (1991) The extended case method, in: M. Burawoy (Ed.) et al. Ethnography Linhound, pp. $271-287$ (Berkeley. CA: University of California Press).

Conroy, M. M. \& Berke. P.R. (2004) What makes a good sustainable development plan? An analysis of factors that influence sustainable development, Enviromment and Planning A, 36(8), pp. 1381- 1396.

Daley, D. M. \& Layton. D. F. (2004) Policy implementation and the Environmental Protection Agency: what factors influence remediation at superfund sites? Policy Studies Journal, 32(3), pp. $375-392$.

Derthick, M. (1972) New Towns In-Town: Why a Federal Program Failed (Washington DC: Urban Institute).

Deyle. R. E. \& Smith, R. A. (1998) Local government compliance with state planning mandates: effect of state implementation in Florida. Joumal of the American Planning Association, 64(4), pp. 457-469.

Elazar, D. J. (1984) American Federalism: A View from the States. 3rd edn. (New York: Harper \& Row).

Game, K.W. (1979) Controlling air pollution: why some states try harder. Policy Studies Journal. 7. pp. $728 \cdots 738$.

Goggin, M. L., Bowman. A. O. M., Lester, J. P. \& O’Toole. L. J., Jr. (1990) Implementation Theory and Practice: Toward a Third Goneration (Glenview, IL: Scott, Foresman/Little, Brown Higher Education).

Kubasek, N. K. \& Silverman, G. S. (1997) Envirommental Lan. 2nd edn. (Upper Saddle River. NJ Prentice-Hall, Inc).

Lester, J. P. \& Goggin, M. L. (1998) Back to the future: the rediscovery of implementation studies. Policy Currents, 8(3), pp. $1-9$.

Mueller, K. J. (1984) Local government implementation of national inspired programs: a comparative analysis, Joumal of Lithan Affairs, 6. pp. 166-178.

Patton. M. Q. (1990) Qualitative Evaluation and Research Methods, 2nd edn. (Newbury Park. CA: Sage Publications).

Pressman, J. L. \& Wildavsky, A. (1973) Implementation (Berkeley, CA: University of California Press).

Ringquist, E. J. (1994) Policy influence and policy responsiveness in state pollution control. Policy. Studie's Journal, 22(1), pp. $25-43$.

Robson, C. (1993) Real World Research: A Resource for Social Scientists and Practitioner-Resesarchers. (Oxford: Blackwell Publishers).

Scott, D.\& Willits, F. K. (1991) Envirommental Concem of Pemsylyania Citizens: Data From A Statewide Survey. Technical Report. A.E. and R.S. 219 (University Park: Pennsylvania State University. Department of Agricultural Economics and Rural Sociology).

Switzer, J. V. (2001) Local government implementation of the Americans with Disabilitics Act: factors affecting statutory compliance. Policy Studies Journal, 29(4), pp. 654 - 662.

USEPA (Environmental Protection Agency) (2000) National Water Quality Inventory: 2000) Report (EPA-841-R-02-001) (Washington DC: USEPA Office of Water).

USEPA (Environmental Protection Agency) (2002) Water Quality Conditions in the United States: A Profile from the 2000 National Water Quality Inventory (EPA-841-F-02-003) (Washington DC: USEPA Office of Water).

USEPA (Environmental Protection Agency) (2004) National Henu of Best Management Practices for Stormuater Phase $1 /$. Available at htlp:/clpub.epa.gov npdes stormwater/menuofbmps menu.cfm (accessed 1 Oclober 2004).

Yin. R. K. (1994) Case Study Research: Design and Methods. 2nd edn. (Thousand Oaks. CA: Sage Publications).

\section{Appendix: Interview questions for local government officials}

(1) How long have you worked for the City/County/Township of X and in what capacity?

(2) What is your background with respect to stormwater management? What is your role with respect to the Phase II program? 
(3) How and when did you learn of the Phase II requirements?

(4) After you learned of these requirements, what was your reaction? (Any perceived benefits? Perceived costs?)

(5) How and when did you learn about the specific requirements your community would need to meet?

(6) How did you learn about the various options (i.e. the BMPs) available for meeting the 6 minimum control measures?

(7) What types of stormwater management activities were already going on in your community? What sort of data do your community have with respect to water quality?

(8) To what extent did the Phase II requirements correspond to efforts already ongoing in your community with respect to stormwater? (i.e. were you already doing some of what Phase II requires?)

(9) Who prepared the permit application (NOI)? What experience/qualifications with regard to stormwater management do they have? (this would include continuing education, such as conferences).

(10) What kinds of resources are/were available in your community for responding to the Phase II requirements? (in terms of personnel, budgets, etc.)

(11) How would you assess your local capacities for responding to the Phase II requirements? (i.e. Were the responsibilities shared by multiple people? What sorts of costs were involved? etc.)

(12) Were any external resources available? (such as guidance from the EPA, state agency, professional associations, etc.) If so, how helpful were these resources?

(13) In developing your permit application, how did you evaluate the various options available for meeting the six minimum control measures?

(14) How did your community decide what BMPs it would implement? What factors influenced those decisions? Iprompt for scientific information and effectiveness, uncertainty, costs, political viability, administrative operability, etc.]

(15) From a planning and design perspective, Measure 5 in particular appears to have a strong connection to land use planning and policy. Was your local planning department involved at all in responding to this measure? If so, how?

(16) Who was responsible for the planning and decision-making process (in terms of developing the local Phase II response)? What was the role of elected officials?

(17) To what extent (if any) were these decisions influenced by previous information and/or stormwater management activities?

(18) To what extent if at all have you begun to implement your BMPs?

(19) What factors are affecting implementation?

(20) How will the program be paid for?

(21) How much interaction did you have with other Phase II applicants? What influenced this level of interaction? At what point did interaction (if any) occur?

(22) To what extent are you aware of the Phase II implementation strategies of other communities?

(23) Do you have any other comments with respect to the Phase II program? 